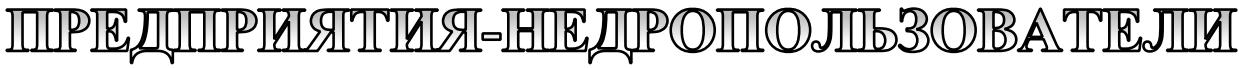

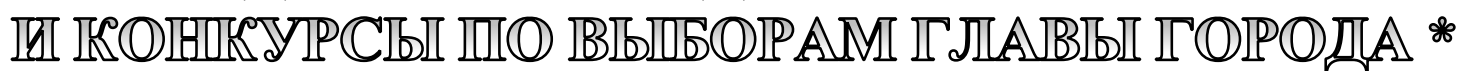

\author{
В.С. Ковин, Пермский федеральный исследовательский центр УрО РАН \\ П.В. Панов, Пермский федеральный исследовательский иентр УрО РАН \\ Р.И. Петрова, Пермский федеральный исследовательский центр УрО РАН
}

Статья продолжает начатый в предыдущем номере цикл публикаций о политических процессах в городах Урала (Пермский край, Свердловская и Челябинская области), в которых деятельность градообразующих предприятий напрямую связана с недропользованием [2]. Анализ проведения конкурсов по выборам главы города показывает, что города, где расположены достаточно крупные предприятия-недропользователи, имеют свою специфику. В целом они более активно участвуют в городской политике, чаще выдвигают своего представителя на позицию главы, консолидируя вокруг себя городские элиты. В то же время эти города соответствуют и общим тенденциям, характерным для политики в промышленных городах Урала. Активность предприятиянедропользователя в городской политике зависит от структуры экономики города, экономического состояния предприятия, а также степени его самостоятельности и заинтересованности менеджмента предприятий в городской политике.

Ключевые слова: промышленные города, недропользование, глава города, конкурсы.

Рациональное недропользование необходимое условие для успешного экономического и социокультурного развития территорий, экологической безопасности и создания комфортных условий проживания. Для городов Урала это имеет особое значение, поскольку в силу исторически сложившейся специализации экономики значительная часть ведущих промышленных предприятий напрямую связана с недропользованием. Речь идет о тех предприятиях, для которых добыча полезных ископаемых является основной деятельностью (добывающая промышленность) либо предварительным этапом для основного производства (ме- таллургия, производство строительных материалов). Масштабы производства на этих предприятиях таковы, что они, как правило, являются градообразующими.

Правда, поставщиками сырья для металлургического производства могут быть другие предприятия, а месторождения, где добывается это сырье, могут располагаться на иных территориях. Поэтому следует отдельно выделить те города, где находятся предприятия, которые ведут промышленную добычу полезных ископаемых на месторождениях, расположенных в границах города. Основываясь на базе данных «Политическое пространство промышленных городов Урала» [5],

\footnotetext{
* Исследование выполнено в рамках программы проект № 18-6-6-29 «Политическое пространство идентичности, практики».

фундаментальных исследований УрО РАН, промышленных городов Урала: институты,
} 
а также на Сводном государственном реестре Российского федерального геологического фонда [7], из всей совокупности промышленных городов Урала (56 городов в Пермском крае, Свердловской и Челябинской областях) были выделены около 20 городов, которые наиболее полно отвечают данным критериям: в городе расположено достаточно крупное предприятие, которое занимается добычей полезных ископаемых как сырья для промышленного производства на месторождениях, находящихся в черте города. Именно для этой категории предприятий, то есть в узком смысле, используется в данной работе понятие «предприятие-недропользователь» ${ }^{1}$

Учитывая, что предприятие-недропользователь ведет свою деятельность в границах города (городского поселения или городского округа), можно предположить, что городские власти и соответствующие предприятия проявляют особую заинтересованность во взаимодействии. В то же время предыдущие исследования, выполненные в рамках данного проекта, показали, что промышленные предприятия Урала демонстрируют весьма высокую вариативность с точки зрения вовлеченности в городскую политику $[1 ; 6]$. Возникает вопрос, как ведут себя в этом отношении «предприятия-недропользователи».

Ключевой властной позицией в политическом пространстве города, очевидно, является должность главы города [8], причем значение ее только усилилось после перехода к так называемой «конкурсной модели». В этой модели глава, будучи избранным депутатами представительного органа из кандидатов, отобранных конкурсной комиссией ${ }^{2}$, непосредственно возглавляет администрацию города. Поэтому активность и эффективность участия предприятия-недропользователя в городской политике достаточно хорошо фиксируется через его участие в конкурcax на должность главы города. Анализ конкурсов проводился на основе методологии, разработанной в предыдущих исследованиях и основывается на двух базовых критериях: конкурентность и конфликтность [3; 4]. В результате установлено, что в городах с предприятиями-недропользователями примерно три четверти конкурсов проходят по типу «неконкурентные $и$ неконфликтHble», тогда как в других промышленных городах Урала такой тип встречается лишь примерно в половине случаев. В значительной мере это объясняется именно тем, что предприятие - недропользователь более активно участвует в городской политике, чаще выдвигает своего представителя на позицию главы, консолидируя вокруг себя городские элиты. Примечательно, что в половине случаев здесь обнаруживается явная аффилиация главы города c градообразующим предприятием ${ }^{3}$ (в других промышленных городах это имеет место лишь в каждом пятом случае). При таком раскладе неудивительно, что в большинстве случаев результаты конкурсов на должность главы города вполне предсказуемы, соперник основного кандидата играет сугубо «техническую» роль, конкурсные процедуры проходят без конфликтов и срывов, а по их завершению депутаты дружно голосуют за консолидированного кандидата.

Вместе с тем вариативность в проведении конкурсов по выборам главы характерна и для городов с предприятиями - недропользователями, поскольку примерно каждый четвертый конкурс здесь был конкурентным и / или конфликтным. Для объяснения этой вариативности мы разбили все города на несколько групп.

\footnotetext{
1 В широком смысле к «недропользователям» относится огромное количество предприятий, поскольку целевое назначение пользования недрами включает в себя самые разнообразные виды работ, вплоть до добычи подземных вод для питьевого, хозяйственно-бытового и технологического водоснабжения.

2 В городских округах и муниципальных районах половина членов конкурсной комиссии назначается представительным органом соответствующего муниципального образования, а другая половина губернатором.

3 Правда, в двух случаях (Серов и Соликамск) глава города - выходец с другого градообразующего предприятия, которое не относится к категории предприятий - недропользователей в том узком понимании, как оно используется в данной работе.
} 
Первая группа -8 городов с единственным доминирующим в экономике города предприятием, которое является недропользователем. Как правило, все они (за исключением Горнозаводскцемента в Горнозаводске) - крупные металлургические заводы (Магнитогорский металлургический комбинат (ММК) в Магнитогорске, принадлежащие УГМК медеплавильные заводы Среднеуральский в Ревде и «Святогор» в Красноуральске, Уфалейникель в Вехнем Уфалее, Карабашмедь в Карабаше) или крупные добывающие производства: Магнезит в Сатке и Учалинский ГОК в Верхнеуральске.

Эти предприятия, казалось бы, должны полностью доминировать и в городской политике; самым ярким примером этого является Магнитогорск - второй по величине город в Челябинской области, население которого составляет около 417 тыс. человек (на 01.01.2018) ${ }^{4}$. Наличие мощного месторождения железной руды предопределило его развитие как одного из крупнейших мировых центров черной металлургии. Магнитогорск имеет статус моногорода и входит в категорию моногородов со стабильной социально-экономической ситуацией. Градообразующее предприятие ММК не только занимает ведущие позиции в социально-экономической жизни города, но и доминирует в политическом пространстве. На протяжении последних пятнадцати лет именно его представители возглавляют городскую власть, а их выдвижение согласует и контролирует руководство предприятия.

Последний конкурс по избранию главы города, прошедший в октябре 2016 г., также не стал исключением. Всего на конкурс заявилось 7 кандидатов, однако до финальных конкурсных процедур дошли только четверо. В качестве основной кандидатуры на пост главы города рассматривался начальник управления капстроительства ММК Сергей Бердников, и депутаты местной легислатуры, большинство их которых аффилированы с градообразующим предприятием, дружно поддержали его кандидатуру на итоговом голосовании.
Вместе с тем в этой же Челябинской области обнаруживается совсем иной случай - Карабаш. Как и Магнитогорск, Карабаш является городом с монопрофильным производством, однако, в отличие от последнего, включен в перечень моногородов с наиболее сложным социально-экономическим положением. Градообразующее предприятие «Карабашмедь» с 2004 г. находится под управлением $3 \mathrm{AO}$ «Русская медная компания», штаб-квартира которой располагается в г. Екатеринбурге. Основной вид деятельности предприятия производство черновой меди из медного концентрата с предварительным обогащением медно-цинковых руд, а также из вторичного медесодержащего сырья. Интенсивное промышленное освоение города привело к тяжелой экологической обстановке, последствия которой пытаются устранить по сей день.

Активного участия в политической жизни города градообразующее предприятие не принимает. А если какие-либо попытки предпринимаются, то заканчиваются пока безуспешно. Показателен в этом плане последний конкурс по избранию главы города, который прошел в декабре 2015 г. На эту должность претендовали пять кандидатов: главный бухгалтер отдела культуры администрации Карабашского городского округа Полина Майорова, директор по правовым и корпоративным вопросам ООО Дженерал Билдинг (расположено в г. Миассе) Олег Буданов, директор ООО Горнолыжный центр «Солнечная долина» Василий Сoрока, пенсионер Александр Сатонин и предприниматель Александр Киприянов. Конкурсная комиссия по итогам собеседования отобрала кандидатуры О. Буданова и В. Сороки, однако заседание думы, на котором должен был определился победитель, не состоялось. По одной из версий, причиной стало нежелание части депутатов, близких к руководству «Карабашмедь», поддерживать «варяга из Миасса» О. Буданова. Разрешить конфликт и провести на должность главы города О. Буданова удалось только после

\footnotetext{
${ }^{4}$ Представленные здесь и ниже описания отдельных случаев по выборам глав городов сделаны на основе многочисленных публикаций в разнообразных средствах массовой информации.
} 
вмешательства региональных властей. Можно предположить, что сложное финансовое положение градообразующего предприятия не позволяет ему играть более заметную роль в политической жизни города. В условии упадка предприятия дополнительная активность и возникшая политическая ответственность могут еще больше усугубить кризис. Сдерживающим фактором в Карабаше, конечно, являлось и понимание невозможности вступления в конфронтацию с региональной властью. Случай Магнитогорска показывает обратное. Это моногород со стабильным экономическим положением градообразующего предприятия. Власть в городе отождествляется с заводом.

Другая группа промышленных городов с предприятиями - недропользователями характеризуется тем, что они являются лишь одним из нескольких значимых для города экономических акторов, причем не всегда ведущим. Эту группу можно разделить на две подгруппы. К первой относятся г. Краснотурьинск (Свердловская область) c Богословским алюминиевым заводом (корпорация Русал), который занимается добычей бокситов; г. Серов (Свердловская область) с Серовским заводом ферросплавов (группа ЧЭМК, Челябинск) - добыча флюсовых известняков и разработка шлакоотвала ферросплавного производства; г. Кировград (Свердловская область) с заводом по производству полиметаллов (филиал «Уралэлектромедь», УГМК) - добыча медно-цинковых колчеданных руд; Кушва (Свердловская область) с Гороблагодатским Рудоуправлением (подразделение ОАО Высокогорский ГОК, Н. Тагил) разработка железорудного месторождения. Сюда же относятся города Пермского края - Березники и Соликамск с «Уралкалием» как главным недропользователем, но в обоих городах есть другие крупные предприятия. Предприятия - недропользователи, представленные в этих городах, как правило, являются достаточно крупными работодателями, входящими в состав холдингов и корпораций.

Вторая подгруппа - города с предприятиями-недропользователями средних масштабов, которые, как правило, добывают не руду, а строительные материалы: г. Богданович (Свердловская область) с OOO «Огнеупоры» - добыча огнеупорных глин; г. Катав-Ивановск (Челябинская область) с «Катавским цементом» (Евроцемент Груп) - добыча цементного сырья; г. Нижняя Тура (Свердловская область) с Минераловатным заводом АО «Тизол» - добыча базальта; г. Сухой Лог (Свердловская область) с «Сухоложскцементом» - добыча цементного сырья.

Социально-экономическое пространство этих городов выглядит более фрагментировано. Казалось бы, и политические процессы должны протекать здесь в более конкурентной среде, так как разные предприятия могут претендовать на свою долю местной власти. Однако это не так. Конкурсы по избранию глав, которые прошли здесь за последние годы, в основном были неконкурентными и неконфликтными. Примечательно, что за исключением Краснотурьинска, Богдановича и Кировграда, избранные главы не связаны с предприятием - недропользователем. При этом переизбранный мэр Краснотурьинска Александр Устинов еще в 2001 г. перешел на работу в администрацию города с должности начальника карьера Богословского алюминиевого завода, то есть хоть и является выходцем с завода, но уже достаточно давно связан с местной администрацией.

Очевидно, что в данных территориях предприятия - недропользователи не спешат взять на себя часть ответственности за городское управление, а предпочитают ее делегировать представителям административных команд или выходцам из иных предприятий. Показателен в этой связи пример «Уралкалия». В Березниках он является опорой для главы города Дьякова, а в соседнем Соликамске предпочитает не вмешиваться в конкуренцию между бумажниками и административной командой. Возможно, одно из объяснений такого поведения менеджмента предприятий - недропользователей в этих городах заключается в том, что они являются подразделениями крупных корпораций, чьи основные интересы сосредоточе- 
ны в других территориях. Средние же предприятия из второй подгруппы, хотя и являются преимущественно «местными», не обладают достаточными кадровыми и иными ресурсами для участия в городской политике.

Исключительным случаем стал конкурс в г. Богдановиче, который прошел в 2017 г. Избрать главу здесь удалось только с третьего раза, поскольку все прежние попытки срывались из-за острого межэлитного противостояния. Летом 2017 г. городом несколько недель одновременно руководили два мэра: избранный еще на прямых выборах и действующий на тот момент Владимир Москвин и избранный депутатами думы Владимир Голованов. После судебных разбирательств, отмены итогов двух первых конкурсов и консультаций в администрации губернатора компромиссной фигурой на посту главы стал главный инженер предприятия - недропользователя «Огнеупоры» Павел Мартьянов. В третьем за год конкурсе приняли участие 13 кандидатов: экс-глава муниципалитета Андрей Быков, заместители главы администрации Елена Жернакова и Алексей Мельников, депутат местной думы Алексей Буслаев, инженер предприятия «Огнеупоры» Павел Мартьянов, действующий мэр Владимир Москвин (также выходец с завода) и еще ряд малоизвестных граждан. В финал конкурса вышли двое: представитель администрации Е. Жернакова и П. Мартьянов, который и получил поддержку 13 из 19 депутатов. Таким образом, предприятие «Огнеупоры» является активным участником политических процессов в городе, стремится сохранить контроль за органами власти. Причина, возможно, кроется в том, что оно является стабильно работающим предприятием, при этом наличие по соседству в регионе сильных игроков на рынке огнеупоров стимулирует менеджмент к активной социальной политике и позиционированию себя перед региональной властью в качестве актора, придающего стабильность территории.
Более характерна для этой группы городов ситуация, которая сложилась в ходе избрания главы Кировграда в октябpe 2017 г. Здесь городская администрация и градообразующее предприятие многие годы работают в тандеме. Действующий глава переизбирается уже в третий раз, а завод лишь выставляет технического кандидата. При этом городская дума занята представителями завода (17 из 20 депутатов). В результате все 20 депутатов единогласно переизбрали Александра Оськина (глава с 2008 г.). Его «техническим» конкурентом был заместитель главного инженера филиала «Производство полиметаллов» акционерного общества «Уралэлектромедь» (филиал УГМК) Виталий Мальков. Таким образом, здесь предприятие - недропользователь удовлетворяется ролью партнера в тандеме администрация-завод, сохраняя в то же время серьезные рычаги контроля через депутатский корпус и подконтрольный электорат.

$$
\text { * * * }
$$

Таким образом, проведенное исследование обнаруживает, что политические процессы в городах, где расположены достаточно крупные предприятия - недропользователи, обладают спецификой. Она связана с тем, что в целом они более активно участвуют в городской политике, чаще выдвигают своего представителя на позицию главы, консолидируя вокруг себя городские элиты. Вместе с тем эти города демонстрируют и значительную вариативность, объяснение которой соответствует общим тенденциям, характерным для политики в промышленных городах Урала. Активность предприятия - недропользователя в городской политике зависит от структуры экономики города, экономического состояния предприятия, а также степени его самостоятельности (самостоятельное или головное предприятие холдинга / один из филиалов холдинга) и характеристик менеджмента предприятий (руководители, имеющие «местное» происхождение, более активно участвуют в городской политике, чем «варяги»). 
Библиографический список

1. Витковская Т.Б. Политическое пространство промышленных городов Урала: крупные предприятия в политике и управлении // Власть и элиты / гл. ред. А.В. Дука. Т.6. - СПб.: Интерсоцис, 2019. - С. 197-215.

2. Кирьянов И.К., Назукина М.В. Символика недропользования в современной геральдике и брендинге уральских городов // Вестник Пермского научного центра. - 2020. - № 2. - С. 76-88.

3. Ковин В.С., Петрова Р.И. Конкурентность в локальном политическом пространстве: конкурсы по избранию глав МСУ и выборы депутатов представительных органов власти в муниципальных районах и городских округах Пермского края в 2012-2017 гг. // Вестник Пермского научного центра УрО РАН. - 2017. - № 4. - С. 112-120.

4. Ковин В.С., Петрова Р.И. Конкурсная модель рекрутирования глав в политическом пространстве промышленных городов Урала: специфика и типология // Ars. Administrandi (Искусство управления). - 2019. - № 2. - С. 267-286.

5. Панов П.В. База данных «Политическое пространство промышленных городов Урала» // Вестник Пермского научного центра. - 2018. - № 3. - С. 77-82.

6. Рябова О.А., Филиппова Е.Ю. Градообразующие предприятия в политическом пространстве промышленных городов Урала: вариативность включенности // Вестник Пермского федерального исследовательского центра. - 2018. - № 4. -С. 81-86.

7. Сводный государственный реестр Российского федерального геологического фонда [Электронный pecypc]. URL: https://www.rfgf.ru/license/index.php (дата обращения: 20.04.2020).

8. Чирикова А.Е., Ледяев В.Г. Власть в малом российском городе. - М.: Издательский Дом ВШЭ, 2017. $-416 \mathrm{c}$.

\title{
SUBSURFACE USERS ENTERPRISES AND CONTESTS FOR THE ELECTION OF THE MAYOR
}

\author{
V.S. Kovin, P.V. Panov, R.I. Petrova \\ Perm Federal Research Center UB RAS
}

The article continues the publication cycle concerning political processes in the cities of the Urals (Perm Krai, Sverdlovsk and Chelyabinsk Oblasts). The activities of city-forming enterprises in those cities are directly related to the subsurface users plants (extractive industry). The analysis of the elective contests of the city mayor shows that the cities where sufficiently large subsurface users enterprises are located have their own specific features. In general, these cities are more actively involved in urban politics, more often put forward their representatives to the position of mayor, consolidating the city elite around themselves. At the same time, these cities meet general requirements trends of urban politics in the industrial cities of the Urals. The activity of the subsurface users enterprises depends on the structure of the city's economy, the economic status of an enterprise, as well as the degree of its independence and the interest of enterprise management in urban politics.

Keywords: industrial cities, subsurface use, mayors, contests.

\section{Сведения об авторах}

Ковин Виталий Сергеевич, кандидат исторических наук, старший научный сотрудник отдела по исследованию политических институтов и процессов, Пермский федеральный исследовательский центр УрО РАН (ПФИЦ УрО РАН), 614990, г. Пермь, ул. Ленина, 13а; e-mail: kovinvit@gmail.com

Панов Петр Вячеславович, доктор политических наук, доцент, главный научный сотрудник отдела по исследованию политических институтов и процессов, ПФИЦ УрО РАН; e-mail: panov.petr@gmail.com

Петрова Регина Игоревна, младший научный сотрудник отдела по исследованию политических институтов и процессов, ПФИЦ УрО РАН; e-mail: rance.regina@mail.ru 